
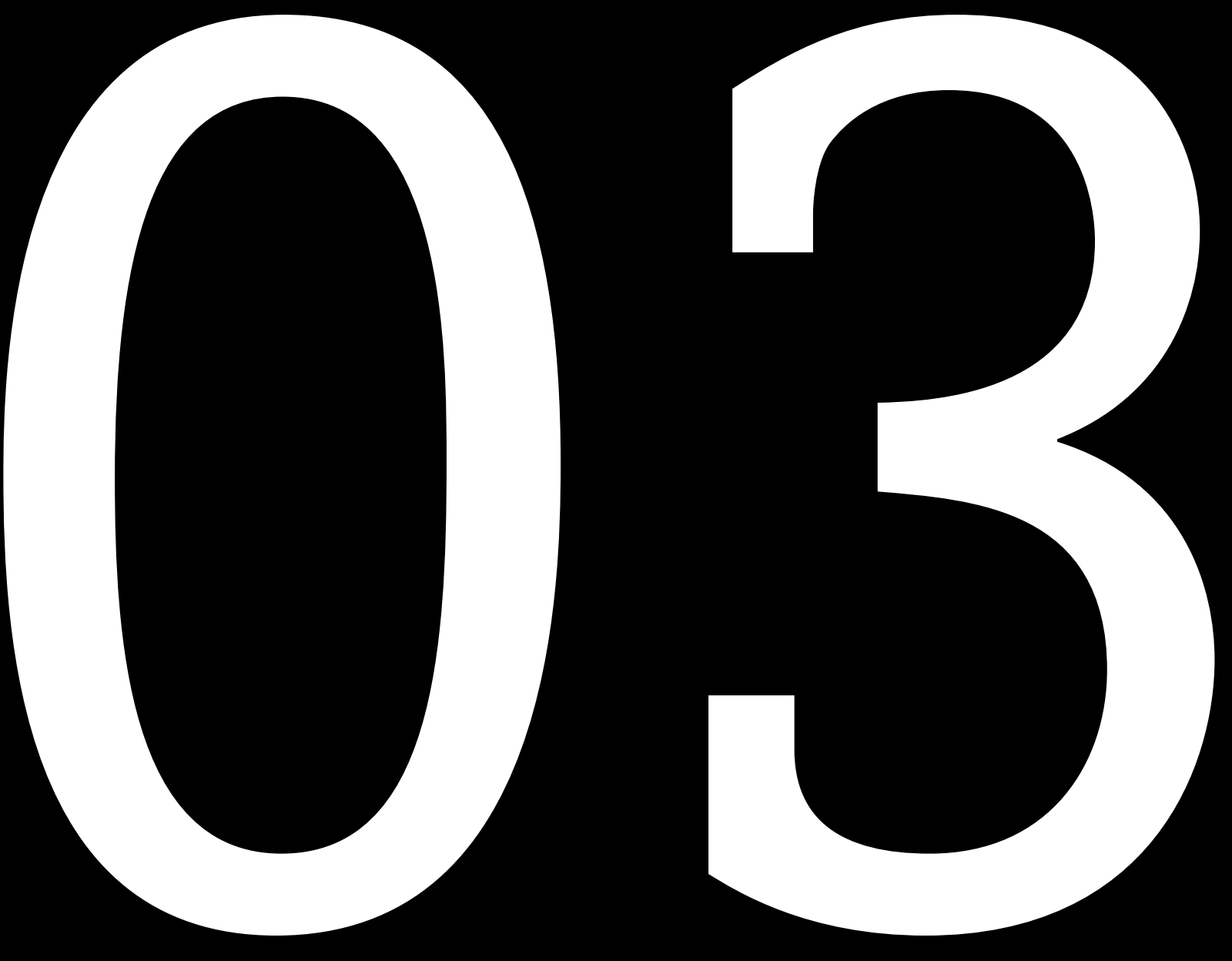

DOI: https://doi.org/10.14483/2422278X.13954 


\section{Memoria histórica en Colombia: subjetividades recomposición del tejido social a través de la narración ${ }^{1}$}

Historical memory in Colombia: Subjectivity and reconstruction of the social fabric through narration

Memória histórica na Colômbia: subjetividades e recomposição do tecido social por meio da narração

\section{Luz Karime Vanegas Niño ${ }^{2}$ Miguel Ángel Tovar Flórez ${ }^{3}$ (i)}

Para citar este artículo: Vanegas, L. K. y Tovar, M. Á. (2019). Memoria histórica en Colombia: subjetividades y recomposición del tejido social a través de la narración. Ciudad Paz-ando, 12(2), 33-43. doi: https://doi.org/10.14483/2422278X.13954

Fecha de recepción: 17 de octubre de 2018

Fecha de aprobación: 10 de octubre de 2019

\footnotetext{
1 Artículo de reflexión de la ponencia "Reconstrucción de la memoria histórica en Colombia: subjetividades y recomposición del tejido social a través de la narración”, presentada en el IV Congreso Latinoamericano de Antropología. Instituto de Investigaciones Antropológicas Universidad Nacional Autónoma de México. 2015

2 Licenciada en Humanidades y Lengua Castellana y magíster en Comunicación-Educación de la Universidad Distrital Francisco José de Caldas. Docente en la Secretaría de Educación de Bogotá. Correo electrónico: luzkarimevn@gmail.com, ORCID: https://orcid.org/0000-0001-6744-3242

3 Licenciado en Humanidades y Lengua Castellana de la Universidad Distrital Francisco José de Caldas y magíster en Investigación Educativa de la Universitat de Lleida (España). Docente en la Secretaría de Educación de Bogotá. Correo electrónico: migueltovarf@gmail.com, ORCID: https:// orcid.org/0000-0002-8683-4756
} 


\section{RESUMEN}

En el marco del proceso de paz en Colombia, el esclarecimiento de los hechos sucedidos durante el conflicto propicia procesos de reconstrucción de la memoria histórica con las voces de las víctimas que "contribuyen a la reparación integral, a las garantías de no repetición y a la construcción de una paz sostenible" (Centro Nacional de Memoria Histórica). Este proyecto busca reflexionar sobre cómo a través del relato se entretejen modos de reconstruir subjetividades, evitando así el desfallecimiento de la memoria. La narración no solo se traduce en el relato que se constituye medio de la oralidad, sino que recurre a diferentes objetos y espacios que son un puente entre las subjetividades y el reconocimiento de las víctimas del conflicto.

Palabras clave: conflicto, memoria histórica, narración, reconstrucción, víctima.

Within the framework of Colombia's peace process, clarifying the events that occurred during the conflict fosters processes to reconstruct historical memory through the victims' voices that 'contribute to comprehensive reparation, ensuring that these events are never repeated and constructing sustainable peace'. This paper seeks to reflect on ways in which different paths of reconstructing subjectivity is interwoven through narratives, thus preventing loss of memories. Narratives not only translate into stories that are constituted through oral communication but also use different objects and spaces that bridge subjectivity and recognise the victims of conflict.

Keywords: conflict, historical memory, narrative, reconstruction, victim.
No âmbito do processo de paz na Colômbia, a clarificação dos
acontecimentos ocorridos durante o conflito propicia proces-
sos de reconstrução da memória histórica com as vozes das
vítimas que "contribuem para a reparação integral, para a ga-
rantia da não repetição e para a construção de uma paz susten-
tável" (Centro Nacional de Memória Histórica). Este projecto
procura reflectir sobre a forma como, através da narrativa, se
entrelaçam as formas de reconstrução das subjectividades,
evitando assim o colapso da memória. A narrativa não só se
traduz na narrativa que constitui o meio da oralidade, como
também recorre a diferentes objectos e espaços que consti-
tuem uma ponte entre as subjectividades e o reconhecimento
das vítimas do conflito.

Palavras-chave: conflito, memória histórica, narração, reconstrução, vítima. 
Están todos muertos. Pero en una historia, que es una especie de sueño, los muertos a veces regresan, se sientan, nos hablan y sonrien al mundo. Tim O’Brien

\section{Introducción}

Después de casi medio siglo de conflicto armado en Colombia, en la última década se han venido entablando esfuerzos para hacer visible la condición de víctima y, así, reconocer otros testimonios que hacen parte de la historia del país. Como fórmula imperativa para un proceso de postconflicto se hace necesaria:

la construcción de la paz en medio de la guerra, mediante el reconocimiento pleno de los derechos de las víctimas a la verdad, la justicia y la reparación integral. Cuenta además con un énfasis especial en las dimensiones individual y colectiva, material y simbólica de dichos derechos. (CNMH, 2014, p. 8)

De esta manera, el recordar se entrelaza con la noción de verdad, y es interés de esta reflexión plantear que a través de ciertas manifestaciones culturales y simbólicas se pueden revivir algunas narrativas sobre el conflicto; estas, sin duda, se consideran fuentes imprescindibles para la construcción de la paz a partir de la memoria y la democratización de voces silenciadas.

¿De qué manera los procesos simbólicos de reconstrucción de la memoria inciden en la subjetividad histórica colombiana a través de la narración? Las narraciones son entendidas como aquellas manifestaciones que crean el puente para reconocer las experiencias del otro y configurar un tercer espacio dado por la historicidad del sujeto en su dimensión temporal, su relación con el espacio y sociabilidad o relaciones interpersonales. Como lo plantea Soja (1997): "el tercer espacio es un espacio vivido como espacio experiencial, además del imaginado. Pero que no sólo se queda allí, sino que está relacionado con la historia; así, el espacio vivido es equivalente al tiempo vivido" (p. 75). Por ende, los individuos asignan significado y sentido a sus vivencias según cómo las habite, perciba o construya a lo largo de su vida, y es esa reconstrucción la que se llama "narración". Este concepto no solo recae en las prácticas de relato a partir de la escritura o la oralidad, que serían tan solo dos formas de narrar, sino otros artefactos como las imágenes (pinturas, bordados, libros, museos, cuerpo, etc.) que permiten la reconstrucción de la memoria, la cual hasta hace unas décadas había sido invisibilizada.

Partiendo de lo anterior, se define memoria como aquel proceso cognitivo que constituye a los sujetos, que les brinda su identidad, su pasado, su ser. Dicho proceso da trascendencia al sujeto y permite "una representación apropiada de una vida que conduce hasta el presente, esto es, una historia de vida modelada en el acto de la autodefinición" (Friedman, 2001, p. 184). Es un acto individual y colectivo en el que se rememoran experiencias que son retratos del pasado con una carga simbólica.

A nivel social, la memoria integra y cohesiona a los grupos sociales a través elementos que proporcionan sentido y construyen un pasado, un presente y un futuro. Es en ese sentido que la memoria colectiva o el recuerdo social puede entenderse como "la evocación colectiva de un pasado común y la conmemoración de acontecimientos que pueden ser previos a la experiencia de cada uno" (Mendoza, 2014, p. 104). Por ello, la construcción de la memoria es de vital importancia para el reconocimiento y apropiación de símbolos colectivos como medio para recuperar el pasado y reconfigurar la historia en aras de un futuro en transición.

En el conflicto armado colombiano se han acallado miles de voces, es decir, durante muchas décadas no se reconocieron en su totalidad a sus actores-víctimas. Como se plantea en el informe ;Basta Ya! (CNMH, 2013a), a menudo se piensa la guerra desde un todo o un nada, el cual se traduce en:

la pretensión totalitaria de exterminar al adversario, o bien en la ilusión de acabar con la violencia sin cambiar nada en la sociedad [...]. En este contexto, es un acontecimiento reciente la emergencia de las víctimas en la escena social y en los ámbitos institucionales y normativos [...] durante décadas, las víctimas fueron ignoradas tras los discursos legitimadores de la guerra, fueron vagamente reconocidas bajo el rótulo genérico de la población civil o, peor aún, bajo el descriptor peyorativo de "daños colaterales”. Desde esta perspectiva, fueron consideradas como un efecto residual de la guerra y no como el núcleo de las regulaciones de esta. (CNMH, 2013, p. 13)

Hay que aclarar que los esfuerzos por reconstruir la memoria como preludio al esclarecimiento de la verdad se estipulan en Colombia desde el 2012 mediante la Ley 1448 (Ley de Víctimas y Restitución de Tierras). Para trazar la ruta que allí se enmarca, tanto las víctimas como el Gobierno han asumido la responsabilidad ética de generar espacios para recrear y revivir la memoria. Así, son recientes la necesidad y las políticas que se encaminan en Colombia para revivir narraciones nunca contadas a través de artefactos que no solo se refieren a objetos físicos.

El espacio, como lo afirma Scheifer (2014), es asumido y resignificado como una práctica social, es decir, un tercer espacio que abarca dimensiones tanto materiales como simbólicas. La noción de espacio, ligada a la noción de tiempo, produce relatos por doquier al expandir los procesos de significación, de reconstrucción de conocimientos, de subjetividades y de relaciones de poder:

Tendo como referência teóricos que afirmam que o espaço não é meramente o pano de fundo estático onde 
a ação sócio-histórica se desenrola, mas um construto social que resulta de uma série de colonizações temporárias problemáticas que dividem e conectam as coisas em diferentes tipos de coletivos ${ }^{4}$. (Scheifer, 2014, p. 7)

El espacio no es estático es simbólico. Es una construcción colectiva emergente que reúne las experiencias de las víctimas: dimensiones materiales, temporales y dialógicas, las cuales llevan a una comprensión de los procesos que interfieren en la construcción e interpretación de significados, así como a la resignificación o transposición semántica, específicamente en el campo espacial en tanto dimensión para reconstruir la memoria en Colombia.

Por otro lado, la narración como ejercicio de recuperación de la memoria ha sido un fuerte referente en la creación de artefactos (espacios y objetos) para la recreación de la historia por parte de las víctimas y de la construcción de sus respectivas subjetividades; ejemplo de ello es el trabajo que ha realizado el Centro de Memoria, Paz y Reconciliación, donde, a través de artefactos de memoria, permite que las víctimas narren historias alrededor de la experiencia vivida en el conflicto armado. Sin duda, la memoria y la narración permiten exteriorizar y visibilizar la historia oculta de casi 60 años de conflicto. Como señala el CNMH (2013a):

Colombia apenas comienza a esclarecer las dimensiones de su propia tragedia, [...] aunque la mayoría de nuestros compatriotas se sienten habitualmente interpelados por diferentes manifestaciones del conflicto armado, pocos tienen una conciencia clara de sus alcances, de sus impactos y de sus mecanismos de reproducción. (p. 13)

Dicha noción de interacción discursiva es concebida como generadora de sentido, puesto que "el discurso es un fenómeno práctico, social y cultural” (Van Dijk, 2000, p. 21) y se conforma en actos sociales que generan interacción social. El discurso como secuencia se pone en funcionamiento para hacer algo, es decir, las personas utilizan el lenguaje para comunicar ideas o creencias (o para expresar emociones) y lo hacen como parte de sucesos sociales más complejos. Estos procesos sociales "más complejos" se refieren a la capacidad cohesiva que parte de la democratización de las voces, propiciando un triángulo para llegar a la verdad y la cohesión social: narración-memoria-subjetividad.

En favor de lograr esto, se han emprendido en Colombia diversos ejercicios de memoria entendidos como los mecanismos, procesos y esfuerzos de una sociedad para

\footnotetext{
4 "Teniendo como referencia teórica que el espacio no es simplemente el fondo estático donde se desarrolla la acción sociohistórica, sino una construcción social que resulta de una serie de colonizaciones temporales problemáticas que dividen y conectan las cosas en diferentes tipos de colectivos" [Traducción propia]
}

confrontar su pasado, permitiendo la reconciliación y la reparación, ello con el fin de buscar la verdad y hacer justicia ${ }^{5}$.

Es interés de esta investigación centrarse en aquellas acciones que de manera imperativa cuentan con la participación de las víctimas en las denominadas "medidas de satisfacción", tal como se estipula en la Ley 1448 de 2011:

Las medidas de satisfacción incluyen la difusión del relato de las víctimas y la búsqueda de la verdad. Por esta razón, la memoria histórica asume un rol clave en la recomposición del tejido social afectado por la violencia y se vuelve parte del patrimonio público de la sociedad con un carácter autónomo e independiente (Arts. 186 y 187, Decreto 4800 de 2011). La construcción de memoria histórica implica el fortalecimiento cultural de su tejido social, a través de la visibilización y fortalecimiento de sus dispositivos particulares de transmisión de memoria. (CNMH, 2014, p. 18)

El eje central de este trabajo es la subjetividad y la construcción de un tercer espacio a partir de ejercicios de la memoria, ello en el marco del conflicto armado colombiano y el esclarecimiento de la verdad. Esta investigación está enmarcada dentro del paradigma cualitativo; en concordancia con Denzin y Lincoln (2003), se toma una perspectiva naturalista y la comprensión interpretativa de la experiencia humana. Aquí se indaga sobre situaciones no medibles desde lo cuantitativo, se parte de las probabilidades y la interpretación del comportamiento humano.

Desde el paradigma cualitativo, se da la necesidad de adoptar un enfoque que permita ilustrar cómo surgen los ejercicios de la memoria a través de la narración de historias con elementos de valor simbólico como objetos, cartografías, mapas, tejidos, entre otros, realizados por las víctimas del conflicto armado. Tal enfoque se relaciona con una mirada descriptiva de los artefactos que sirven como puente para construir memoria y, en consecuencia, pueden ser una opción hacia las vías del duelo y el perdón de los afectados. Ahora bien, cabe mencionar que:

la memoria de las víctimas es diversa en sus expresiones, en sus contenidos y en sus usos. Hay memorias confinadas al ámbito privado, en algunos casos de manera forzosa y en otras por elección, pero hay memorias militantes, convertidas a menudo en resistencias. (CNMH, 2013a, p. 14)

La tarea, en consonancia con Hernández, Fernández y Baptista (2014), es describir y evaluar diversos aspectos desde el paradigma cualitativo, concretamente lo que

5 Para ampliarinformación remitirse al documento “Guía de medidas de 
atañe a los procesos de memoria, duelo y restauración que realizan las víctimas. Los artefactos de la memoria son vistos como elementos simbólicos que permiten narrar historias de vida, hilar recuerdos sobre situaciones traumáticas y contar la verdad de las víctimas sobre diversas experiencias directas con el conflicto.

Los momentos en esta empresa son: (a) apartes sobre la historia de la violencia en Colombia; (b) voces de las víctimas; (c) reflexiones sobre los artefactos de memoria y su dimensión simbólica como tercer espacio (construcción de una subjetividad colectiva que reconozca "esa otra historia" contada desde la mirada de las víctimas); (d) la narración.

En este sentido, el alcance del trabajo es descriptivo, se enmarca en la reflexión sobre los fines de la memoria histórica en el marco del posconflicto. De acuerdo con Hernández, Fernández y Baptista (2014), la investigación descriptiva busca especificar propiedades, características y rasgos importantes de cualquier fenómeno que se analice. En este caso, se hizo una pausa con el fin de reconocer las metodologías de los trabajos de memoria que actualmente se impulsan desde el Área de Memoria Histórica del CNMH.

Posteriormente, se plantea una discusión sobre la construcción de un tercer espacio simbólico a partir de los artefactos y narrativas de memoria. Las narrativas son producto de experiencias, en este caso de los individuos a quienes se les ha vulnerado la mayoría de derechos por causa del conflicto armado, son la puerta para visibilizar las vivencias traumáticas, construir memoria, identidad social y la búsqueda de la no repetición.

También se consideran importantes "porque a través de estas los actores sociales suelen recordar y ordenar sus carreras o remembranzas como una serie de crónicas narrativas, o sea, series de relatos marcadas por acontecimientos clave" (Coffey y Atkinson, 2003, p. 66).

\section{La historia en Colombia}

Los últimos sesenta años de la historia de Colombia han estado marcados por la violencia, los ataques de los grupos al margen de la ley, el desplazamiento forzado y las desapariciones de personas, esto ha sido el común denominador y ha determinado fuertemente a las últimas cuatro generaciones. De esta manera, toda la ciudadanía se ha visto implicada directa e indirectamente en el conflicto.

Según cifras del CNMH, entre el 1 de enero de 1958 y el 31 de diciembre de 2012 murieron aproximadamente 220000 personas, esta cifra equivale a la cantidad de habitantes de las ciudades mexicanas Campeche o Monclova, o las ciudades colombianas Sincelejo o Popayán.

Sin embargo, no hay cifras exactas debido a que hay un gran número de posibles denuncias quedan relegadas al silencio social o colectivo, el miedo todavía fragmenta las voces del conflicto, o también por factores metodológicos y logísticos al momento de captar y registrar información. Ahora bien, en la última década el Estado ha puesto en marcha mecanismos e instituciones que se encargan de ejecutar lo dispuesto en la Ley de Víctimas, con lo cual recientemente se empezaron a dimensionar los alcances del conflicto y, con ello, a visibilizar las voces de las víctimas.

Cifras alarmantes han venido auscultándose al tiempo que salen a la luz pública nuevos informes que recopilan las cifras de la violencia. Ocho de cada diez muertos en situación de conflicto armado son civiles. Se indica en los informes que:

De estas muertes el 81,5\% corresponde a civiles y el $18,5 \%$ a combatientes; es decir que aproximadamente ocho de cada diez muertos han sido civiles, y que, por lo tanto, son ellos - personas no combatientes, según el Derecho Internacional Humanitario- los más afectados por la violencia. (CNMH, 2013a, p. 32)

Comprender la violencia comporta conocer cómo ha sido su evolución a lo largo de los años. De acuerdo con el informe CNMH (2013a), el crecimiento del conflicto armado se puede dimensionar en cuatro momentos cronológicos, a saber: (a) la violencia bipartidista se transforma en violencia subversiva (1958-1982); (b) expansión guerrillera, políticas de paz y eclosión paramilitar (19821996); (c) los años de la tragedia humanitaria, la expansión de guerrillas y paramilitares, el Estado a la deriva y la lucha a sangre y fuego por el territorio (1996-2005); (d) las AUC negocian y se desmovilizan, el Estado empuja a las Farc a sus retaguardias (2005-2012).

Dadas las condiciones de violencia, prácticamente la historia de Colombia está fragmentada, no solo en el factor de línea del tiempo (hechos desconocidos en razón de que nadie los ha relatado), sino que entre regiones sucede algo similar: hay regiones más golpeadas que otras. En el sector rural, que corresponde al $70 \%$ de la geografía nacional, es donde han ocurrido los hechos violentos más recrudecidos. Con respecto a las grandes urbes, aunque han sucedido acontecimientos en el marco de la violencia, las huellas más dolorosas se encuentran a cientos de kilómetros de estas.

En este orden de ideas, es posible que la recuperación de la memoria tanto en víctimas como en victimarios y demás población civil mejore la cohesión social y reescriban la historia del país. Aclarar la verdad para la no repetición y la reparación seguramente reconfigurará la historia de Colombia.

\section{Los hechos violentos y las diversas voces (fragmentación de la historia)}

\author{
El mundo se tornó inseguro, y las personas \\ se vieron obligadas a desplegar mecanismos de protección \\ como el silencio
}


la desconfianza y el aislamiento. Esto modificó sustancialmente las relaciones comunitarias y familiares. Centro Nacional de Memoria Histórica (2013a, p. 263)

A la fecha, se cuenta con información que ilustra las dimensiones del conflicto armado, como las cerca de 220000 personas que han fallecido en circunstancias de la violencia. Sin embargo, el panorama revelado por el Grupo de Memoria Histórica señala que probablemente haya crímenes que todavía no se conocen; varias hipótesis surgen sobre ello: por amenazas de los victimarios frente a sus víctimas, por el miedo como consecuencia de la violencia y el desplazamiento (en el caso que los hechos hayan ocurrido hace años, pero todavía no se han dado a conocer), porque las víctimas, por la magnitud del conflicto, son invisibilizadas frente a otros discursos más o menos institucionales, entre otras causas.

Respecto a los hechos violentos, los resultados de investigaciones a lo largo del país muestran que:

la violencia prolongada durante más de 50 años y su progresiva degradación han generado impactos y daños devastadores tanto para las víctimas, familiares, comunidades y organizaciones e instituciones públicas, como para el conjunto de la sociedad colombiana. Los impactos son complejos, de diverso orden, magnitud y naturaleza. (CNMH, 2013a, p. 259)

Los efectos negativos son cuantiosos en cuanto a número de muertos y estructuras físicas afectadas; sin embargo, hay otros efectos más devastadores como los proyectos de vida fracturados de familias y generaciones, la sensación de miedo constante, el silencio causado por el horror y el cierre de las opciones de mejora hacia el futuro. Cabe mencionar que "Los impactos psicológicos deterioran las relaciones interpersonales y la salud física, las pérdidas económicas generan inestabilidad emocional, los impactos colectivos y el daño a las redes sociales y comunitarias afectan las capacidades y posibilidades individuales" (CNMH, 2013a, p. 260). Adicionalmente, la sensación de angustia y desarraigo de lugar y de familia cercenan el deseo de poner en evidencia los testimonios de dolor.

Consecuencia de lo anterior es que las voces de las víctimas son acalladas, con ello se mantiene al margen parte de la historia. Por lo anterior, se podría afirmar que la historia en Colombia se ha fragmentado, por lo que es difícil mantener como verdadera la premisa de que la historia que se narra en los libros de referencia, la que se ilustra en las instituciones educativas y la que se imparte abiertamente, abarca la legítima historia del país, sobre todo en el periodo de la violencia.

En este orden de ideas, es imperativo reconocer a profundidad la evolución del conflicto, no basta con informarse acerca de las víctimas. Cabe mencionar respecto a la memoria histórica que:

[su] definición se encuentra menos clarificada en las ciencias sociales, pero que se ha popularizado como escenario donde hoy se discuten con potencia las cuestiones acerca de la memoria como un problema de la sociedad, de políticas que rebasan a un grupo determinable de afectados por acontecimientos concretos. (Antequera, 2011, p. 35)

Esta última resulta entonces necesaria para significar y completar la cronología y el mapa de sucesos que han fracturado, pero que al mismo tiempo han definido a Colombia.

\section{Víctimas: invisibles y desaparecidos individual y socialmente}

\author{
La verdad y la memoria histórica para que \\ los hechos de violencia no se repitan [...] La verdad \\ para que se reconozca socialmente a las víctimas. \\ (Segundo encuentro de organizaciones de víctimas,
}

2004)

En el año 2012, salió a la luz la Ley de Víctimas, en esta se exponen las obligaciones del Estado en los ámbitos de la verdad, la justica y la reparación; desde ese momento, las víctimas han empezado a visibilizarse por medio de sus narraciones. Hay que reconocer que durante el conflicto armado las víctimas han soportado todo tipo de estigmatización y flagelos, desde la revictimización que promueven los victimarios antes y después de que la víctima denuncie hasta la estigmatización y segregación social producto del desplazamiento forzado. Al respecto, la Ruta Pacífica de las Mujeres (2013) refiere que en la historia de Colombia numerosos hombres y mujeres que han sido testigos o han participado en procesos de investigación en colaboración con la justicia posteriormente han resultado asesinados. En consecuencia, se desencadenan migraciones masivas de las víctimas hacia las grandes ciudades y pobreza por falta de atención oportuna del Estado.

Los efectos negativos son innumerables, pero quizás uno de los más difíciles de sanar es el miedo, un "mecanismo defensivo eficaz, [el cual] se convierte en una emoción paralizante y mortificadora que impide que algunas personas puedan adelantar actividades esenciales para desarrollar sus vidas, como salir de sus hogares, caminar por el campo, reunirse con sus amistades" (CNMH, 2013a, p. 263). Lo anterior en relación directa con el clima del terror que los combatientes (tanto Ejército como grupos al margen de la ley), sembraron en los territorios de conflicto. 
El miedo a las retaliaciones que se pudieran dar en el ámbito del conflicto armado también tiene implicaciones psicológicas que, además de afectar las relaciones sociales, conlleva a que la moral y la autoestima se deterioren, y que el silencio se apodere de los testimonios y los recuerdos traumáticos. En muchos casos, de manera voluntaria o no, las víctimas borran los rastros, las huellas y los recuerdos; con todo, el miedo fuerza a que las víctimas caigan en el silencio y se autoinvisibilicen.

Así las cosas, la invisibilidad no solo afecta a las víctimas en el plano individual, también permea la esfera social, altera las representaciones sociales tanto de sí mismas como de quienes están alrededor. Ante este panorama, se retoma la pregunta que formula Metz (2003):

¿Qué sucedería si alguna vez los hombres pudieran defenderse con el arma del olvido de la infelicidad presente en el mundo, si pudieran construir su felicidad sobre el olvido inmisericorde de las víctimas, sobre una cultura de la amnesia en la que solo el tiempo se encargara de curar las heridas? (p. 170)

Esta última invita a ubicar a las víctimas en sus dimensiones espacio-temporales y a ubicarse a sí mismo en igual sentido.

Los trabajos y metodologías de la memoria buscan restablecer y construir la memoria histórica, pues implican la construcción de sujetos sociales. Al respecto, León y Zemelman (1997) entienden la memoria "como la experiencia y la utopía que tiene, como núcleo constituyente, un valor heurístico y hermenéutico para comprender uno de los aspectos esenciales del análisis de los sujetos sociales: la configuración de sus proyectos y su viabilización" (p. 68).

En este sentido, las víctimas deben ser reconocidas como sujetos sociales por medio de escenarios y dinámicas que propendan a la reparación, el perdón y la verdad; por otro lado, la sociedad en general tiene la responsabilidad de implicarse desde los trabajos de la memoria hacia la reconstrucción del pasado histórico, ello a partir de la violencia y el flagelo. En otras palabras, se busca la construcción de la memoria colectiva. Esta se podría denominar la memoria de hechos colectivos, pero el actor puede ser uno o varios sujetos independientes y aislados. En síntesis, se propende por la democracia y reconstruir parte de la historia oculta de Colombia a partir de hechos desconocidos (invisibilizados), pero que entrañan la verdad de las víctimas frente a lo que ha sucedido durante el conflicto.

\section{Los artefactos y el tercer espacio: los puentes}

Un objeto se vuelve artefacto de varias maneras, para el caso de la memoria, ésta puede ser la traza: el objeto es algo que tiene estabilidad y fijeza en el tiempo, espacio o lenguaje, en él se depositan experiencias significativas. Mendoza (2014, p. 107)

Una metodología que permite vehiculizar estos procesos consiste en configurar narraciones a partir de distintos objetos materiales y la elaboración conjunta de artefactos simbólicos en los que se visualicen hechos concretos, se haga catarsis de los recuerdos más dolorosos y se ponga en evidencia lo siguiente:

[esa] "otra historia", esa "otra verdad", sobre acontecimientos que han definido la historia de Colombia. Así pues, "el testimonio puede ser pensado como un tipo de autobiografía donde se unen -y refuerzan - dos imaginarios de verdad y realidad: no sólo los hechos que tuvieron lugar sino también la propia experiencia que suscitan”. (Arfuch, 2010, p. 85)

Lo anterior implica (re)construir una memoria compartida. Como se dijo líneas atrás, no solo recae en un testimonio escrito u oral, sino en diversas manifestaciones simbólicas que permiten la reconstrucción del ser en un espacio, tiempo y sociabilidad determinada.

Por tanto, abordar la memoria a partir de artefactos productores de narración tales como objetos personales, imágenes, elaboración conjunta de cartografías, líneas del tiempo, tejido, gastronomía, entre otras, significa trascender a una esfera simbólica en la que se materializa el recuerdo y se visibilizan las voces del conflicto. Es una dinámica en la que se traslapan imágenes del pasado, que en la medida en que se dicen se teje un camino discursivo que vehiculiza no solamente una prosopografía lineal sobre los acontecimientos y lugares del pasado, sino que es la manera en la cual las víctimas traen al presente el dolor, la angustia y todo un marco de situaciones que han alterado por completo sus vidas.

Al respecto, Arfuch (2010) reflexiona acerca de la relación de imágenes y narración, pues considera que son los elementos fundamentales sobre los cuales se dinamiza la transmisión de memoria. Menciona que:

se unen de modo indisociable [...] tanto por la dinámica icónica de la palabra, que hace de todo relato una pantalla proyectiva de nuestra imaginación, como por el carácter narrativo de la imagen, aunque ésta requiera a menudo de la vecindad de la palabra. En ambos casos evoca una intencionalidad [...] que pone en juego el movimiento dialógico del discurso. (Arfuch, 2010, p. 67)

Por ende, tejer narrativas con imágenes y objetos permite rememorar los hechos, los lugares, los sentimientos, la ausencia, los momentos crueles. 
Con todo, se considera que los artefactos de memoria sirven como puente para hacer un ejercicio profundo, el cual suscita traer al presente las voces acalladas. Significa configurar un espacio simbólico en el que las narrativas de las víctimas dinamizan un encuentro de construcción de memoria colectiva, memoria histórica, catarsis, decir el discurso, contar su verdad. Para las víctimas y las no víctimas es un espacio de alteridad en el que cada individuo, a través de la conversación, del señalar y connotar imágenes, se pone en evidencia con el otro. Las víctimas también toman postura en el mundo y son reconocidos al narrar sus experiencias y esa "otra verdad". Es posible que, a partir de ello, las no víctimas reconfiguren sus referentes sobre historia, de manera que interioricen hechos hasta ahora desconocidos.

\section{La narración como catarsis y subjetividad}

Cada vivencia es un momento de la vida infinito. Schleiermacher

La guerra, el conflicto y la vulneración de los derechos conllevan a la búsqueda de aquellas historias que rememoren los hechos acontecidos. Sin embargo, las víctimas en medio del dolor de su sufrimiento van poco a poco desapareciendo de la esfera social, al punto de perder cualquier indicio de su propio yo. Se trata de trasladar dichas narraciones de una esfera íntima que ha sido juzgada y menospreciada, a un ámbito público que brinde el reconocimiento a las voces de aquellos que no han hablado, que se han ocultado.

Se considera la creación de un "espacio biográfico" que en una de sus dimensiones postula el descentramiento del sujeto, como lo plantea Arfuch (2010): "se vincula a la "razón dialógica", de raíz bajtiniana: el sujeto debe ser pensado a partir de su 'otredad', del contexto de diálogo que da sentido a su discurso" (p. 12). En ese sentido, la narración de los sucesos vividos permite reconstituir la subjetividad de las víctimas.

Es así que la narración como estrategia de reconstrucción social empieza con la restitución individual. Es un trabajo arduo dado que las víctimas del conflicto se han acostumbrado a desaparecer, a callar, a creerse sujetos no fundamentales en la sociedad; sus voces silenciadas caminan junto a nociones como: impunidad, discriminación, democracia fallida, etc. Por ello los esfuerzos en favor de lograr que a partir de la narración se consolide un reconocimiento de sí mismos, de su pasado, de lo que eran antes de vivir el conflicto, de lo que sucedió posteriormente y de la forma en la que en este momento se configuran.

En algunos casos, cuando las víctimas pueden realizar ejercicios de narración de sus experiencias a otras personas, se reconocen como seres con un gran poder social y, de esta manera, al ser escuchadas, empiezan a visibilizarse, a tomar un rol social, a ser partícipes con sus vivencias y sufrimientos, a reconstituirse a sí mismos. Por ende, la narración es vista como catalizadora en tanto que puede favorecer y promover el proceso de recordar y sanar, de revivir a nivel social y de encontrarse con sus sentimientos. Como afirma Arfuch (2010):

Lo vivido es siempre vivido por uno mismo, y forma parte de su significado el que pertenezca a la unidad de este "uno mismo [...] se encuentra una relación inmediata con el todo, con la totalidad de la vida [...] así el giro obligado de toda narrativa, como proceso temporal esencialmente transformador impone su materia: contar la historia de una vida es dar vida a esa historia”. (p. 38)

Esta afirmación refleja la manera en la que el relato privado, contado y dado a conocer permite "salvar" la vida íntima del sujeto, le permite reconocerse a través de asumirse como la primera persona dentro de su propia narración, negociar y generar nuevos significados. Según Gadamer citado en Durero (2006) "la comprensión consiste en un diálogo infinito que permite reconfigurar permanentemente nuestras perspectivas de mundo y que da lugar a nuevas interpretaciones que nos acercan de unos a otros significados". Dicha construcción de sentidos y significados es dada a partir del sujeto que antes era desconocido, entramando una narración cargada de vivencias y afectividad que lleva de la exploración de una dimensión interna a una social.

Esto es fundamental para cada una las etapas del proceso colombiano de reconocimiento a las víctimas, de la historia y la verdad. Se debe empezar por reconstruir la memoria de las víctimas, que las víctimas se narren, se reconozcan y adquieran una voz propia. A partir de allí, el proceso es largo y necesario para trazar el camino del que tanto, últimamente, se ha hablado: el posconflicto.

\section{La narración como constructora de historia}

$$
\begin{aligned}
& \text { La pluralidad de las narrativas —en tanto posibilidad de } \\
& \text { afirmación de voces otras-, que abren nuevos espacios } \\
& \text { para lo social, la búsqueda de valores compartidos y } \\
& \text { de nuevos sentidos de comunidad y de democracia. }
\end{aligned}
$$

Arfuch (2010)

Hacer visibles las voces que reivindiquen la historia es una necesidad de dejar testimonio. Hacer público lo vivido conlleva a que el otro se reconozca dentro de la historia y valide la narración como parte de una historia que no ha sido reconocida. Este proceso de alteridad es un puente entre lo individual y lo colectivo, el cual tiene como fin revelar y descubrir lo antes invisible. 
La historia como conciencia colectiva se refiere a las creencias compartidas y a las actitudes morales que funcionan como una fuerza unificadora dentro de la sociedad, la cual se encuentra separada y es dominante en comparación con la conciencia individual. La sociedad, una nación o un grupo, constituyen una entidad que se comporta como un individuo global; así, la historia se crea a partir de fragmentos difíciles de recomponer.

En países como Colombia, sumido en una guerra de décadas, la historia se muestra esquiva, con estelas de humo que ocultan hechos trascendentales. Pocos conocen otras versiones de la historia fuera de la oficial, de la que se transmite institucionalmente y que, además, hasta hace muy poco era reproducida sin cuestionamientos.

Conocer otras voces, visibilizar otras narraciones y darle trascendencia a los sujetos que vivieron los hechos en primera persona permite ir reconstruyendo la historia; en otras palabras, hallar apartes de otras verdades (las de las víctimas). Este proceso requiere de toda una estrategia de interpretación y visibilización de los hechos a través de la memoria, pues para la reparación debe existir diversidad de voces que legitimen otras narraciones no reconocidas.

Recordar los hechos violentos es una condición necesaria para el esclarecimiento de la verdad sobre lo sucedido a las víctimas. Implica reconocer las narrativas plurales y complejas que existen sobre el conflicto y hacer frente a las tensiones que surgen de los sentimientos de venganza acumulados y el deseo de perdón y transformación en la sociedad. En ese proceso de construcción de memoria, promover la difusión de las múltiples voces silenciadas y las narrativas de las víctimas constituye un acto responsable, ético y democrático (CNMH, 2013b, p. 8).

La memoria histórica está inacabada e incompleta $y$, como lo plantea Joinet citado por Andreu-Guzmán (2012), la sociedad tiene derecho a saber y a conocer la verdad sobre lo que ha sucedido para poder determinar las circunstancias sociales, políticas, culturales y económicas que condujeron a dichas violaciones de los derechos humanos. Propone, dentro de algunas de las estrategias para lograr el esclarecimiento de la verdad, la recopilación de las historias de vida de las víctimas y enfatiza en el "deber de la memoria" del Estado y el papel de la memoria histórica en la materialización de ese deber y la prevención de los hechos violentos ya acaecidos.

La narración como mediadora de la verdad es un proceso que debe ser público, no censurado y reconocido legalmente, puesto que solo de esta manera se podrá concebir que la historia no es una sola, sino una telaraña de vivencias, significados y voces que deben tener eco a nivel social.

\section{La narración como cohesión e identidad social}

Construir memoria es un acto político y una práctica social. La memoria es un campo en tensión donde se construyen y refuerzan o retan y transforman jerarquías, desigualdades y exclusiones sociales. También es una esfera donde se tejen legitimidades, amistades y enemistades políticas y sociales. Centro Nacional de Memoria Histórica (2013b, p. 24)

La identidad centra una gran cantidad de categorías de la sociedad y la cultura: valores, educación, roles, región, género, etc. Además, como lo plantea Barbero (1993), también conceptos de "marginación social, de expoliación económica y de exclusión en las decisiones políticas" (p. 16). Así, la sociedad dentro de sus pluralismos culturales y su multiplicidad de experiencias comunicativas produce continuamente símbolos e imágenes que permiten construir identidades que se van aprendiendo. La identidad se construye con el diálogo y el intercambio, y contienen elementos socialmente compartidos que devienen de lo privado que se pone en común y se legitima.

En lo que concierne a esta investigación, la narración es vista como generadora de representaciones que definen a distintos actores sociales. Así:

la pertenencia social implica compartir, aunque sea parcialmente, lo modelos culturales (de tipo simbólico expresivo) de los grupos o colectivos en cuestión [...] La cultura interviene como fuente de identidad: no, por cierto, en términos generales y abstractos, sino en cuanto se condensa en forma de "mundos distintos de sentido", esto es, en forma de "mundos concretos y relativamente delimitados de creencias y prácticas” (Sewell, Jr.; 1999, 52) (Giménez, 2007, p. 63)

La narración como vehículo de identidad social y colectiva implica grandes esfuerzos por dar reconocimiento a las voces de las víctimas; además, más allá de esto, procura estrategias para vincular a la población en general desde distintos ámbitos a la identificación de su yo en la historia que se va descubriendo. Tiene que ver, de igual manera, con poder incluir a la sociedad en general como partícipes de la historia y como legitimadores de la misma. De esta manera, son relevantes los procesos de comunicación en estas dinámicas culturales de creación de significados comunes por medio de acciones colectivas, los cuales den estatus a las diversas narraciones de las víctimas y a la introducción de los hechos contados dentro de una nueva historia colombiana.

Sin duda, se debe abogar por acceder a nuevos campos de acción menos cerrados y delimitados en los cuales haya un lenguaje compartido y unas prácticas que generen adhesión colectiva por medio de la interacción de valores y obligaciones morales, obligando a la población a responder con un rol social determinado dentro de la historia y de las proyecciones en el marco del posconflicto.

Sin desconocer los procesos actuales que hablan del colapso de las identidades, así como de la hibridación de las mismas, y que supone el reinado de las identidades 
individuales por encima de las colectivas, se aboga por fortalecer el tejido social, ya que, como lo afirma Jenkins (1996), la identidad constituye un elemento vital de la vida social hasta el punto de que sin ella sería inconcebible la interacción social-sentido de las acciones realizadas por los actores. Sin identidad simplemente no habría sociedad.

Crear nuevos códigos, nuevos valores, una nueva historia narrada no por los entes oficiales, sino por sujetos desapercibidos e invisibilizados, en la mayoría de los casos de forma intencional (como se menciona en el apartado "La historia en Colombia" a través de las cifras de desaparecidos durante el conflicto armado), es una reivindicación que puede llevar a constituir otras creencias compartidas a nivel colectivo, a generar una fuerza unificadora que se encuentra separada y dominada, a dejar huellas y legados para el futuro.

La narración, en tanto forma de comunicar, permite ese intercambio de nuevos significados, siendo una posible base para la construcción de la identidad social que trabaja por la abolición de las barreras y las exclusiones sociales y simbólicas (Barbero, 1993). Por tanto, la narración permite el acceso y la apertura a otras experiencias y a la producción de significados y sentidos, llegando hasta la transformación de la misma historia.

De modo que la narración, más allá de ser un ejercicio íntimo-personal, tiene el potencial de hacer parte de un largo proceso de construcción de significados dentro de un entramado sociocultural; hace parte de la democratización y pluralización de las voces con el fin de que sean reconocidas, transformadoras y, a la vez, unificadoras.

\section{A modo de conclusión: la narración para la no repetición}

La Ley 1448 de 2011, en su artículo 149 (garantías de no repetición), plantea que:

el Estado colombiano adoptará, entre otras, las siguientes garantías de no repetición: [...] b) La verificación de los hechos y la difusión pública y completa de la verdad, en la medida en que no provoque más daños innecesarios a la víctima, los testigos u otras personas, ni cree un peligro para su seguridad; [...] e) La creación de una pedagogía social que promueva los valores constitucionales que fundan la reconciliación, en relación con los hechos acaecidos en la verdad histórica; [...] i) Fortalecimiento de la participación efectiva de las poblaciones vulneradas y/o vulnerables, en sus escenarios comunitarios, sociales y políticos, para contribuir al ejercicio y goce efectivo de sus derechos culturales. (Congreso de la República de Colombia, 2011)

De esta manera, uno de los fines de conocer y reconocer la verdad y reconstruir la historia colombiana, así como de intentar llevar las historias narradas por las víctimas a la sociedad en general, es la no repetición. Al mencionar en el apartado anterior la creación de una identidad social que permita cohesionar la sociedad se tiene como propósito el reconocimiento de los grandes sufrimientos de la población colombiana a lo largo de los años, sus antecedentes, sus causas, sus efectos; así, se procura no volver a las prácticas violentas ni a causar, de nuevo, tales sufrimientos.

Se pretende no solo escuchar una voz, sino democratizar las voces, darle cabida a todas aquellas narraciones que deben contar su parte de la historia "operará, prioritariamente, como orden narrativo y orientación ética, en esa modelización de hábitos, costumbres, sentimientos y prácticas que es constitutiva del orden social" (Arfuch, 2010 , p. 29). Con ello, se busca preservar la memoria histórica y la no repetición de los hechos victimizantes por medio del conocimiento del otro y, por ende, de nosotros mismos, ya que:

[el escuchar] entraña la posibilidad de un progreso moral, que se traduciría en la extensión de nuestra comprensión de los seres humanos en tanto incluidos en un nosotros, y, por lo tanto, susceptibles de despertar nuestra solidaridad [...] la exploración de las fuentes morales a través de la resonancia personal. Vuelta entonces sobre el sí mismo" que solicita a su vez un mayor compromiso respecto de la justicia, la benevolencia y el altruismo. Así, la ética de la vida personal es vista como indisociable del espacio mayor de una filosofía política. (Arfuch, 2010, p. 86)

La narración, como estrategia de ejercitar la memoria, ayuda a reconstruir el pasado, a conocerlo, a revivirlo, a negociar nuevas prácticas, nuevos estilos de vida. Darle sentido a la narración es pensar la sociedad desde una perspectiva de la alteridad en la que el otro es aquel que se cuenta, cuenta la historia, pero no efímeramente por narrar, sino para trascender, para redefinir como sociedad y, a partir, de la comprensión, transformar y no repetir.

\section{Referencias}

Andreu-Guzmán, F. (2012). Derecho a la verdad y derecho internacional. Bogotá: Comisión Colombiana de Juristas.

Antequera, J. (2011). Memoria histórica como relato emblemático. Consideraciones en medio de la emergencia de politicas de memoria en Colombia. (Tesis de maestría). Bogotá, Pontificia Universidad Javeriana.

Arfuch, L. (2010). El espacio biográfico. Buenos Aires: Fondo de Cultura Económica.

Barbero, M. (1993). Industrias culturales: modernidad e identidad. Anàlisi. Quaderns de Comunicació $i$ Cultura, 15, 9-20.

Centro Nacional de Memoria Histórica CNMH (2013a). ¡Basta ya! Colombia: memorias de guerra y dignidad. Bo- 
gotá: CNMH. Recuperado de http://www.centrodememoriahistorica.gov.co/descargas/informes2013/ bastaYa/basta-ya-colombia-memorias-de-guerra-y-dignidad-2016.pdf

Centro Nacional de Memoria Histórica CNMH (2013b). Recordar y narrar el conflicto: herramientas para reconstruir memoria histórica. Bogotá: CNMH. Recuperado de http://www.centrodememoriahistorica.gov.co/ descargas/informes2009/recordar-narrar-el-conflicto.pdf

Centro Nacional de Memoria Histórica CNMH (2014). Memoria histórica en el ámbito territorial: orientaciones para autoridades territoriales. Bogotá: $\mathrm{CNMH}$. Recuperado de http://www.centrodememoriahistorica. gov.co/descargas/informes2015/autoridadesTerritoriales/memoria-historica-ambito-local-orientaciones-autoridades-territoriales.pdf

Coffey, A. y Atkinson, P. (2002). Encontrar el sentido a los datos cualitativos. Medellín: Universidad de Antioquia.

Congreso de la República de Colombia (2011). Ley 1448 del 10 de junio de 2011.

Denzin, N. y Lincoln, Y. (2003). Collecting and Interpreting Qualitatives Materials. Londres: Sage Publication.

Durero, D. (2006). Relato autobiográfico einterpretación: una concepción narrativa de la identidad personal. Athenea Digital, 9, 131-151. https://doi.org/10.5565/ rev/athenead/v1n9.264

Friedman, J. (2001). Identidad cultural y proceso global. Buenos Aires: Amorrortu Editores.

Giménez, G. (2007). Estudios sobre la cultura y las identidades sociales. México: Conaculta. https://doi.org/10.2307/j.ctvdmwzr4
Hernández, R., Fernández, C. y Baptista, P. (2014). Metodología de la investigación. México: McGraw-Hill.

Jenkins, R. (1996). Social Identity. Londres: Routledge.

León, E. y Zemelman H. (1997). El magma constitutivo de la historicidad. En Subjetividad: umbrales del pensamiento social (pp. 36-72). Barcelona: Anthropos.

Mendoza, J. (2014). La configuración de la memoria colectiva: los artefactos. Por caso, la escritura y las imágenes. Entreciencias, 2(3), 103-119. https://doi.org/10.21933/j.edsc.2014.03.041

Metz, J. (2003). Dios contra el mito de la eternidad del tiempo. En J. Mardones y M. Reyes (Eds.), La ética ante las víctimas. Barcelona: Anthropos.

Ruta Pacífica de las Mujeres (2013). La verdad de las mujeres. Víctimas del conflicto armado en Colombia. Recuperado de https://www.jep.gov.co/Sala-de-Prensa/ Documents/La\%20verdad\%20de\%20la\%20mujeres $\% 20$ (Tomo\%202)\%20(1).pdf

Scheifer, C. (2014). Espaço-temporalidade, ressemiotização e letramentos: um estudo sobre os movimentos de significação no terceiro espaço. São Paulo: Universidade Estadual de Campinas.

Soja, E. (1997). El tercer espacio. Ampliando el horizonte de la imaginación geográfica. Geográfikos, 8, 71-76.

Subcomité Técnico de Medidas de Satisfacción. (2011). Guía de medidas de satisfacción. Recuperado de https://www.unidadvictimas.gov.co/sites/default/files/documentosbiblioteca/274guiademedidasdesatisfaccion.pdf

Van Dijk, T. (2000). El discurso como interacción social. Barcelona: Gedisa. 